\title{
Male partners of adolescent girls and young women: Relationship characteristics and HIV risk-Findings from DREAMS implementation science research
}

Population Council

Follow this and additional works at: https://knowledgecommons.popcouncil.org/departments_sbsr-hiv

Part of the Demography, Population, and Ecology Commons, Family, Life Course, and Society Commons, Gender and Sexuality Commons, International Public Health Commons, and the Women's Health Commons How does access to this work benefit you? Let us know!

\section{Recommended Citation}

Population Council. 2018. "Male partners of adolescent girls and young women: Relationship characteristics and HIV risk-Findings from DREAMS implementation science research," DREAMS Results Brief. Washington, DC: Population Council. 


\section{MALE PARTNERS OF ADOLESCENT GIRLS AND YOUNG WOMEN: RELATIONSHIP CHARACTERISTICS AND HIV RISK}

FINDINGS FROM DREAMS IMPLEMENTATION SCIENCE RESEARCH

South Africa has the largest HIV epidemic in the world, with an estimated seven million people living with HIV. ${ }^{1}$ Rates of new infections among adolescent girls and young women (AGYW) aged 15-24 years are more than four times greater than that of their male peers. ${ }^{2}$ AGYW in South Africa, as in many countries, are particularly vulnerable to HIV for a variety of reasons, including economic disadvantage and unequal power dynamics in sexual relationships with their male partners-many of whom are older and engage in high-risk behaviors. ${ }^{3}$ Additionally, men are much less likely than women to know their status, initiate and sustain on HIV treatment, and are more likely to die of AIDS ${ }^{3,4}$-harming both themselves and their partners.

In an effort to learn more about men's relationships with AGYW and how HIV services can better engage them, the Population Council is conducting implementation science research in KwaZulu-Natal (KZN) Province. This brief reports findings from a 2017 baseline survey with nearly 1,000 men. An endline survey is planned for midlate 2018, and will focus on understanding the successes and challenges of DREAMS and other programming to engage men in HIV services.

\section{METHODS}

The study was conducted in two informal settlements in eThekwini district in KZN (Figure 1). Umlazi is an urban informal settlement area linked with large businesses of the Durban port; area serving smaller industries.

\section{KEY FINDINGS}

An innovative mapping strategy enabled us to reach high-risk men.

More than half of men reported multiple concurrent partnerships with AGYW and older partners in the last year.

Relationships were often transactional and characterized by inconsistent condom use.

Two-thirds of participants reported testing for HIV in the last year.

Most HIV-positive respondents reported current use of antiretroviral therapy (ART), though only half had ever had a viral load test and fewer were aware if they were virally suppressed.

\section{Local Research Partner: Epicentre}

Location: eThekwini district in KwaZuluNatal province, South Africa

Study Duration: 2016-2018

Funder: Bill \& Melinda Gates Foundation

For more information, contact Ann Gottert (agottert@popcouncil.org), Julie Pulerwitz (jpulerwitz@popcouncil.org),or Cherie Cawood (Cheriec@epicentre.org.za). 
This study is part of a portfolio of implementation science studies the Population Council is conducting with funding from the Bill \& Melinda Gates Foundation, related to the DREAMS (Determined, Resilient, Empowered AIDS-free, Mentored, and Safe) Partnership. DREAMS aims to significantly reduce new HIV infections among AGYW in 10 countries in sub-Saharan Africa, including South Africa. Our studies are exploring how to find the most vulnerable AGYW and their male partners, how to characterize these vulnerable populations to better inform targeted programming, and assessing the reach and effect of interventions in reducing HIV risk among AGYW.

Trained interviewers administered a baseline survey from June to September 2017 to a total of 962 men, ages $20-40$.

\section{How did we find AGYW's male partners?}

We used a two-pronged strategy, recruiting men at community "hot spots" where men and AGYW interact and at HIV service sites. Hot spot venues were identified by key informants and included drinking establishments, taxi ranks, and universities. HIV service sites included both facility-based and non-facility-based sites (e.g., home-based or mobile services). Twothirds were recruited at hot spot venues (67 percent) and one-third at HIV service sites (33 percent).

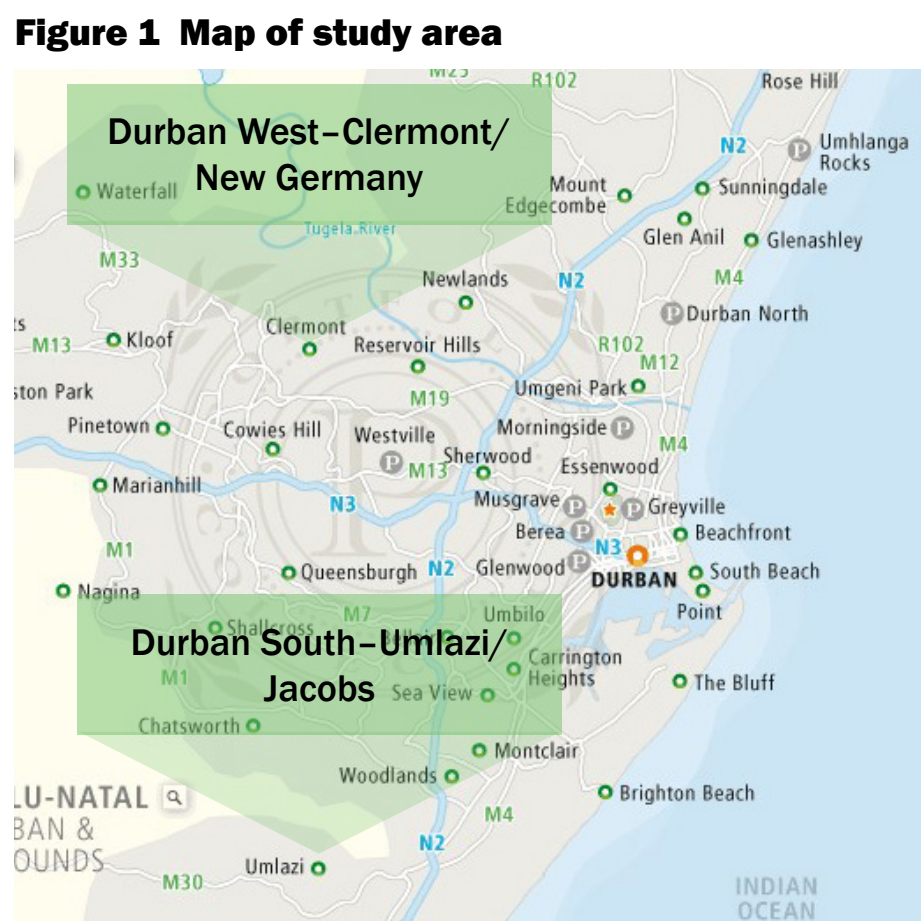

Who are the 962 men who participated in the survey?

Mean age: 28;

range $20-40$ years

$75 \%$ were in casual relationships;

$15 \%$ were married or cohabiting

$59 \%$ had at least one biological child
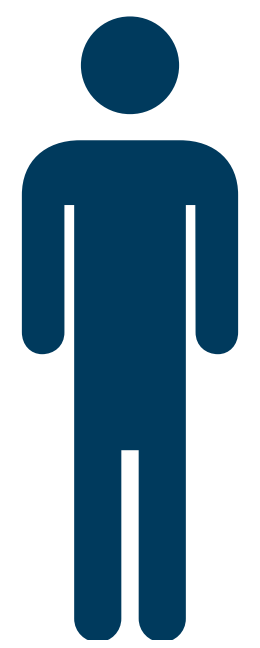

\section{$71 \%$ had completed high school}

\section{1\% were employed}

Most common occupations: taxi/ bus driver; small business owner/ entrepreneur; factory worker; construction worker/craftsman; and informal worker/laborer 


\section{RESULTS}

Nearly three-fourths of men had at least one AGYW partner in the last year.
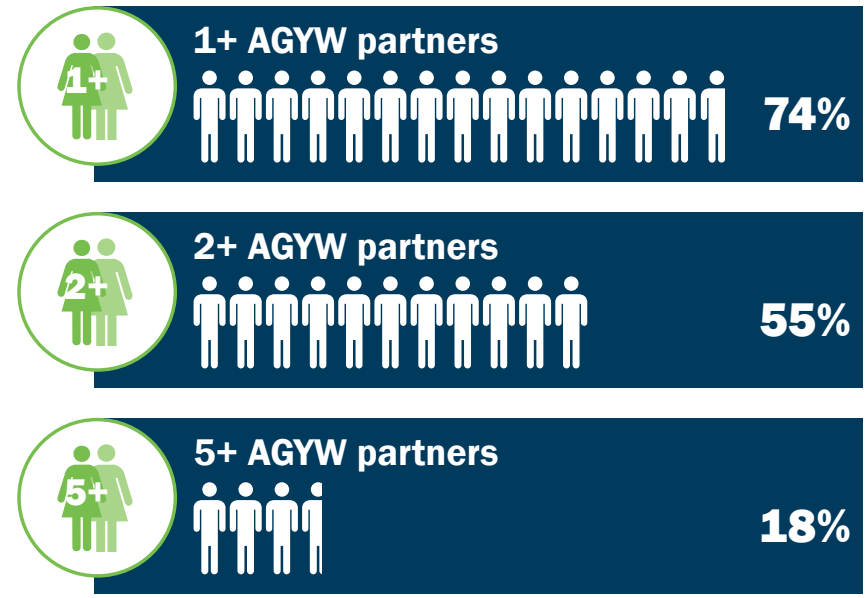

When asked about the age difference with their last three partners, on average, men reported their AGYW partners were 4.6 years younger than them. Among their last three partners, 13 percent reported an age gap of ten years or more. When asked about all of their relationships within the past year, 54\% reported having both AGYW partners and partners 25 years and older.

\section{About half of men's relationships were} transactional in nature and characterized by inconsistent condom use. However, most men knew of their partner's HIV status.

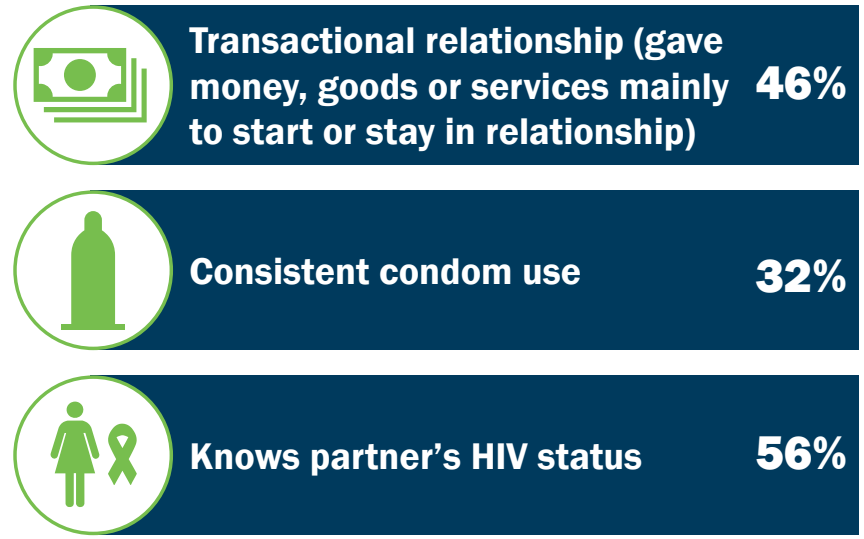

Note: With current or most recent partner
Almost a third of the men had only recently tested for HIV for the first time.

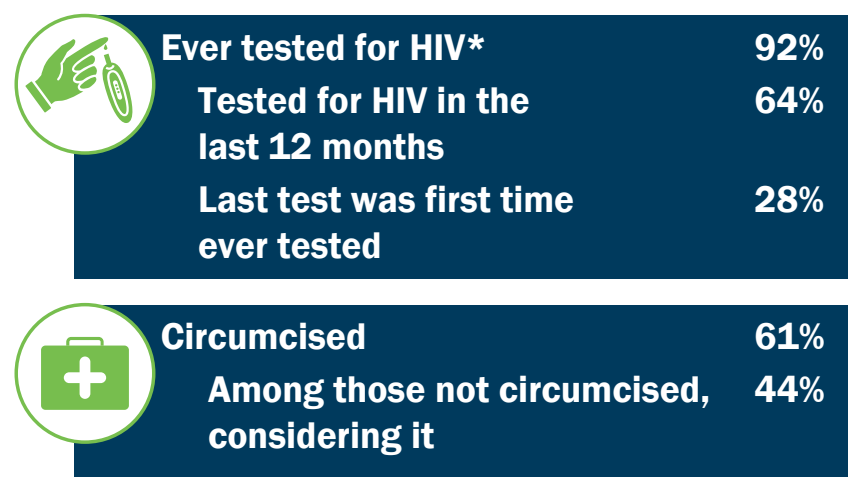

* Restricted to sub-sample recruited at hot spots $(n=649)$ since HIV testing among service users was common.

Men living with HIV had high connectivity to HIV treatment, but limited awareness of viral suppression.

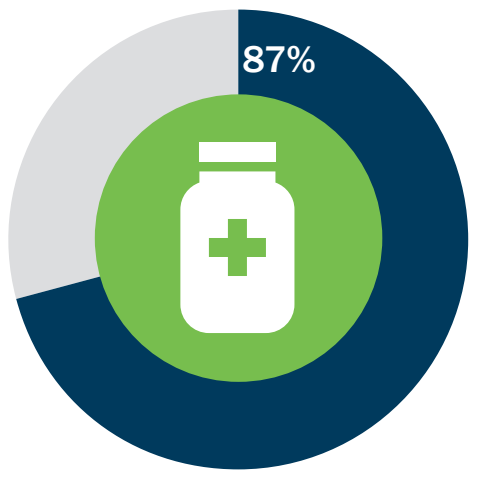

Currently on antiretroviral treatment (ART)

Ever stopped taking ART for at least 1 month

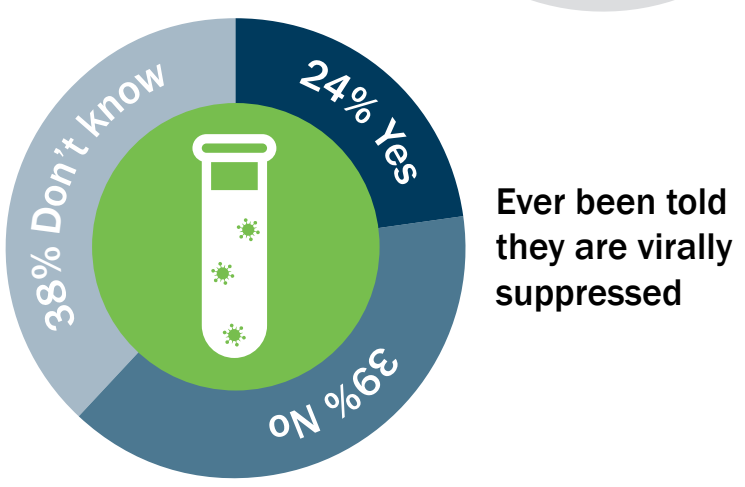

Note: $n=84$ 


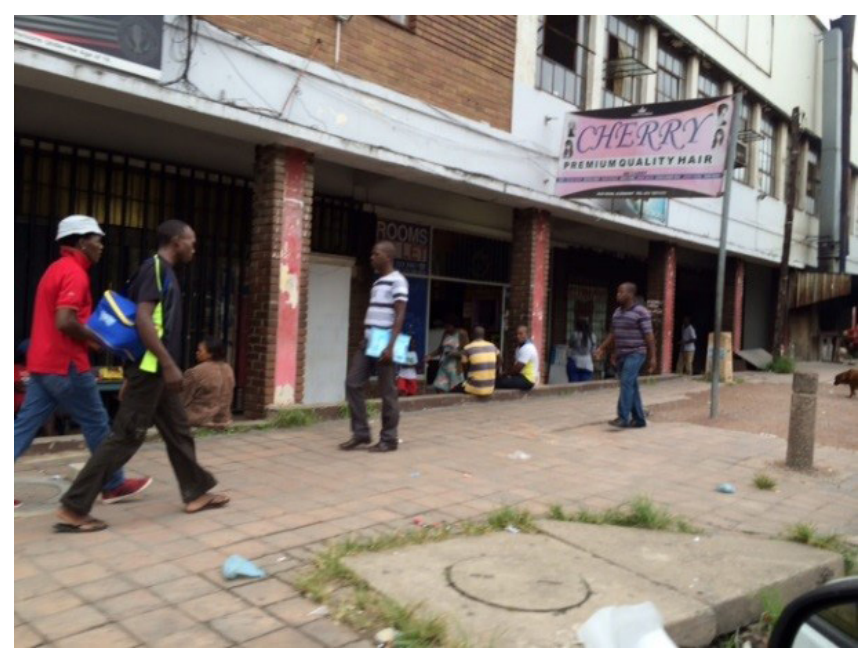

Engaging high-risk men in HIV prevention efforts is critical to reduce their HIV risk as well as that of their partners.

\section{REFERENCES}

${ }^{1}$ Avert. 2017. "HIV and AIDS in South Africa."

Accessed on 30 March 2017. Http://www.avert.org/ professionals/hiv-around-world/sub-saharan-africa/ south-africa\#footnote1_weh798k.

${ }^{2}$ Shisana, O. et al. 2014. South African National HIV Prevalence, Incidence and Behavior Survey 2012. Cape Town: HSRC Press.

3UNAIDS. 2016. "Prevention GAP report." Geneva: UNAIDS

${ }^{4}$ Orr, N. et al. 2017. “Development of a national campaign addressing South African men's fears about HIV counseling and testing and antiretroviral treatment," Journal of Acquired Immune Deficiency Syndromes 74 (Suppl 1): S69-S73.

${ }^{5}$ de Oliveira, T. et al. 2017. "Transmission networks and risk of HIV infection in KwaZulu-Natal, South Africa: a community-wide phylogenetic study," The Lancet HIV 4(1): e41-e50.

${ }^{6}$ Grobler, A. et al. 2017. "Progress of UNAIDS 90-90-90 targets in a district in KwaZulu-Natal, South Africa, with high HIV burden, in the HIPSS study: a household-based complex multilevel community survey," The Lancet HIV 4(11): e505-e13.

\section{IMPLICATIONS}

- Community mapping is a good strategy to identify and reach high-risk men.

- Engaging men in HIV prevention is critical given their multiple age disparate partnerships-a key driver of HIV transmission. ${ }^{5}$

- High-risk partnership behaviors combined with low consistency of condom use highlight the critical importance of primary prevention alongside biomedical prevention efforts. ${ }^{3}$

- Efforts to reach high-risk men with HIV testing and circumcision services need to be sustained.

- Men living with HIV reported high levels of ART use and adherence, but need to be better informed about their viral load suppression.

POPULATION COUNCIL

Ideas. Evidence. Impact.
The Population Council confronts critical health and development issues-from stopping the spread of HIV to improving reproductive health and ensuring that young people lead full and productive lives. Through biomedical, social science and public health research in about 50 countries, the Council works with our partners to deliver solutions that lead to more effective policies, programs, and technologies to improve lives worldwide. Established in 1952 and headquartered in New York, the Council is a nongovernmental, nonprofit organization with an international board of trustees. popcouncil.org

Suggested citation: Population Council. 2018. "Male partners of adolescent girls and young women: relationship characteristics and HIV risk-findings from DREAMS implementation science research," DREAMS Results Brief. Washington, DC: Population Council. 